\title{
Taxonomical and biological notes on Sabethes (Peytonulus) fabricii Lane \& Cerqueira (Diptera: Culicidae)
}

\author{
J. Alencar ${ }^{a *}$ and H. R. Gil-Santana ${ }^{a}$ \\ ${ }^{a}$ Laboratório de Diptera, Instituto Oswaldo Cruz, Avenida Brasil, 4365, CEP 21040-360, Rio de Janeiro, RJ, Brazil \\ *e-mail: jalencar@ioc.fiocruz.br
}

Received: May 12, 14 - Accepted: July 9, 2014 - Distributed: November 30, 2015

(With 9 figures)

\begin{abstract}
Morphological features that remained uncertain in previous identification keys and descriptions of Sabethes fabricii were evaluated based on species type material and two recently collected males. As a result, the following features of Sa.fabricii should be considered: proboscis with a white ventral spot beyond the middle and variably enlarged to the apex, possibly spatulate in males; setae over root of wing yellowish and may be occasionally brownish, mainly in their basal portion; and proctiger ending in four teeth. Additionally, the first record of bamboo as a natural breeding site for Sa. fabricii as well as the first register of this species in the state of Minas Gerais, Brazil are reported here.
\end{abstract}

Keywords: bamboo, identification keys, Neotropical, Sabethini.

\section{Notas taxonômicas e biológicas sobre Sabethes (Peytonulus) fabricii Lane \& Cerqueira (Diptera: Culicidae)}

\section{Resumo}

Caracteres morfológicos que permaneceram incertos em chaves para identificação anteriores e descrições de Sabethes fabricii, foram avaliados com base em material tipo e dois machos recentemente coletados. Como resultado, os seguintes caracteres de Sa. fabricii devem ser considerados: probóscide variavelmente alargada para o ápice, possivelmente espatulada em machos e com uma mancha branca ventral localizada além do seu ponto médio; cerdas sobre a raiz das asas amareladas, podendo ser ocasionalmente marrons, principalmente na sua porção basal, e proctiger com quatro dentes na porção terminal. Adicionalmente, registram-se pela primeira vez, o Bambu como um criadouro natural para Sa. fabricii, bem como a presença dessa espécie para o estado de Minas Gerais, Brasil.

Palavras-chave: bambu, chaves de identificação, Neotropical, Sabethini.

\section{Introduction}

When describing Sabethes fabricii, Lane and Cerqueira (1942) furnished the descriptions of the male, pupa and larva of this species. The types of Sa. fabricii were the male holotype and a female considered as an "allotype" from Rio de Janeiro State, Brazil (Lane and Cerqueira, 1942). In their key for Sabethes Robineau-Desvoidy, 1827 adults, the setae over root of wing were described as yellowish-brown for six species of Sabethes spp., including Sa. fabricii. Additionally, the ventral surface of the proboscis was considered as dark as its dorsal portion for Sa.fabricii and Sa. undosus Coquillett, 1906 (couplet “13.”), yet having a bronzy or white spot or stripe for the other four species diagnosed in the following couplets. Their key for male genitalia diagnosed Sa. fabricii as having three terminal teeth in the proctiger ["tenth sternite"] (couplet "11."). However, before the formal description of this species, in a short discussion on the differences between Sa. fabricii and other closely related species, the white color on ventral surface of proboscis and brownish setae over root of wing were emphasized as characteristic of $\mathrm{Sa}$. fabricii. In the description of the male of this species, the proboscis is noted as very enlarged in its distal third and with a ventral white spot and proctiger ["tenth sternite"] ending in three or four teeth.

Lane (1953) provided few details on the female of Sa. fabricii, for which the setae was brown over root of wing and the ventral surface of proboscis was white. On the other hand, in his key for females of Sabethes, Sa. fabricii is diagnosed as having the "root of wing with yellowish setae" (couplet "12."), and the ventral surface of the proboscis as being "dark, similar to the dorsal one" (couplet "13."). In his key for male genitalia, Sa. fabricii is considered as having three terminal teeth in the proctiger and Sa. tarsopus with four (couplet "11."). The description of the male of Sa. fabricii by Lane (1953) is the same as Lane and Cerqueira (1942), including the mention of the 
proctiger ending in three or four teeth, beyond including the States of Paraná and São Paulo within the geographic distribution of this species.

The key for adults of Sabethes furnished by Forattini (1965) considered the root of wing of Sa. fabricii as bearing yellowish setae (couplet " 5 ") and its proboscis as entirely dark both in the dorsal and ventral portions (couplet "6"), while his key for male genitalia did not mention the proctiger of this species. The key for adults of Sabethes by Forattini (2002) considered the proboscis of Sa. fabricii entirely dark as well (couplet "8").

Harbach (1991) transferred Sa. fabricii from the subgenus Sabethinus Lutz, 1904, in which it had been included originally (Lane and Cerqueira, 1942), to the new subgenus of Sabethes he created, Peytonulus Harbach.

Guimarães et al. (2000) recorded the collection of three females of Sa. fabricii attracted by human bait in a forested area of Serra do Mar State Park, São Paulo State, Brazil.

\section{Material and Methods}

Several species were collected in a recent survey of culicids bred in bamboo in the Hydroelectric Complex of Simplício (HSS-Simplício), Além Paraíba (21 53' 16" S e $42^{\circ} 42^{\prime} 16^{\prime}$ 'W; $140 \mathrm{~m}$ ) (Figure 1), Minas Gerais State. The vegetation of the study area consists of altered native "Atlantic Forest", pastures and remnants of woody vegetation. The mesothermal climate of the study area consists of hot and rainy summers, with a maximum temperature of $37.4{ }^{\circ} \mathrm{C}$ and a minimum temperature of

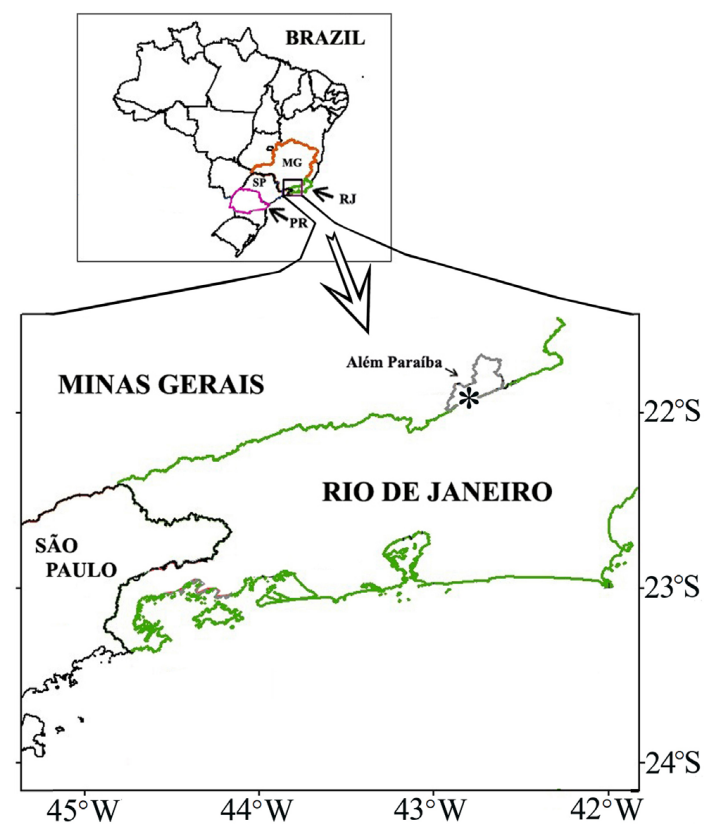

Figure 1. Map of Brazil, showing in the detail portions of the states of Rio de Janeiro, Minas Gerais and São Paulo. Asterisk indicates the new collecting site of Sabethes fabricii. MG - Minas Gerais, PR - Paraná, RJ - Rio de Janeiro, SP - São Paulo.
$14.2{ }^{\circ} \mathrm{C}$ (Köppen). The collection site was characterized by secondary vegetation of the Atlantic Forest, floristic restoration similar to the original structure, recomposition with predominantly bamboo grove monoculture, intense anthropic action and richness in ornamental plants typical of the region.

Identification of the species followed Lane and Cerqueira (1942), Lane (1953), and Forattini (1965, 2002).

The material-type of Sabethes fabricii, a female "allotype" and male holotype, deposited in Entomological Collection of Oswaldo Cruz Institute (IOC) were examined.

\section{Results}

Among the species collected, two males of Sabethes sp. were identified as Sa.fabricii after some doubt caused by the misinformation among the keys for species of this genus as described above. In order to confirm the identification and clarify the diagnostic features of Sa. fabricii, the types of this species, which are maintained in the Entomological Collection of the Oswaldo Cruz Institute (CEIOC), were examined and compared with the specimens newly collected.

The two specimens of Sa.fabricii from the Simplício location were bred from immature forms collected in two diverse species of bamboo in February and October of 2009. Both immature forms were found in internodes less than one meter above ground in the locality "Aurora Farm" ( $21^{\circ} 55^{\prime} 01.2^{\prime \prime} \mathrm{S}$ e $\left.42^{\circ} 48^{\prime} 18.7^{\prime \prime} \mathrm{W}\right)$ in the area of Hydroelectric Complexo of Simplício (HSS- Simplício), Além Paraíba city, Minas Gerais State (Figure 1).

\section{Discussion}

The two specimens of Sa.fabricii from the Simplício location are in accordance with the previous descriptions of Sa. fabricii. Regarding the uncertain features commented on above, the following were observed: proboscis with a large white spot beyond the midsection (Figures 2-4), somewhat more extensive in one specimen (Figure 4); proboscis enlarged in the distal portion in one male (Figure 3 ) and clearly spatulate in the other (Figure 4); yellowish setae over root of wing, in which some were brownish, mainly in their basal portion; and proctiger (in the male in which the genitalia was dissected) ending in four teeth (Figure 5).

In the holotype of Sa. fabricii (Figures 6-9), the proboscis is very enlarged, spatulate in the distal portion with a large white spot beyond the middle (Figure 7); setae over root of wing yellowish; proctiger with four teeth at the apex (Figure 8), but on one side, the subapical tooth is much reduced (Figure 9). Of note in description of the species, Lane and Cerqueira (1942) mentioned the proctiger ["tenth sternite"] with three or four teeth, which may seem somewhat unclear, given this description was based on just one specimen of the holotype male. However, as one side of the proctiger has a reduced tooth (Figure 9), they may have considered a possible variation of this feature.

The "allotype" female shows the proboscis to be slightly enlarged in the distal portion, with a white stripe beyond the middle and the setae over root of wing yellowish. 

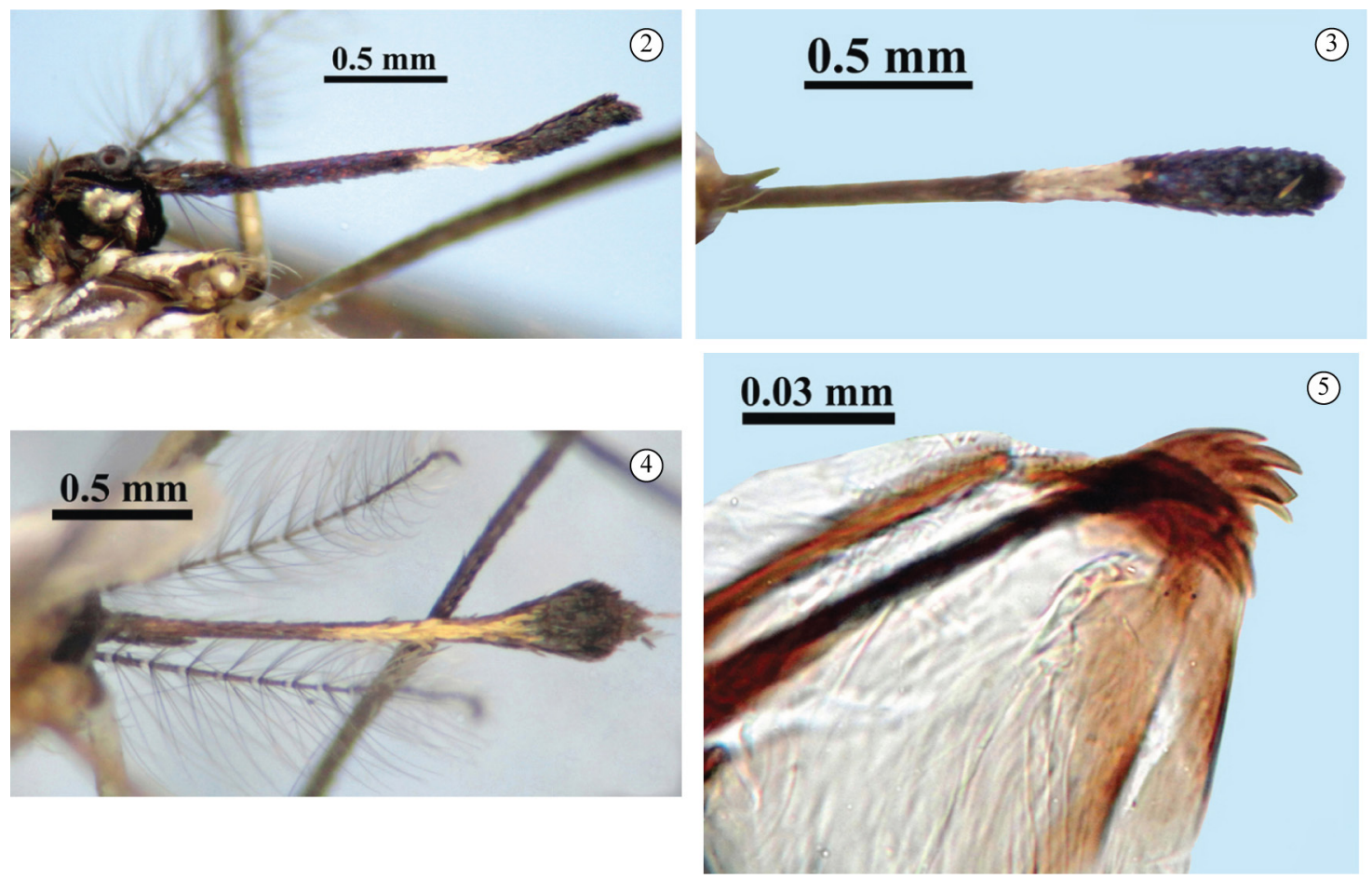

Figures 2-5. Males of Sabethes fabricii from Simplício, Além Paraíba, Minas Gerais State, Brazil. 2-4. proboscis; 2 and 3 . first male; 2. lateral view; 3 . ventral view; 4 . second male, ventral view; 5 . apex of proctiger of one male showing the apical teeth.
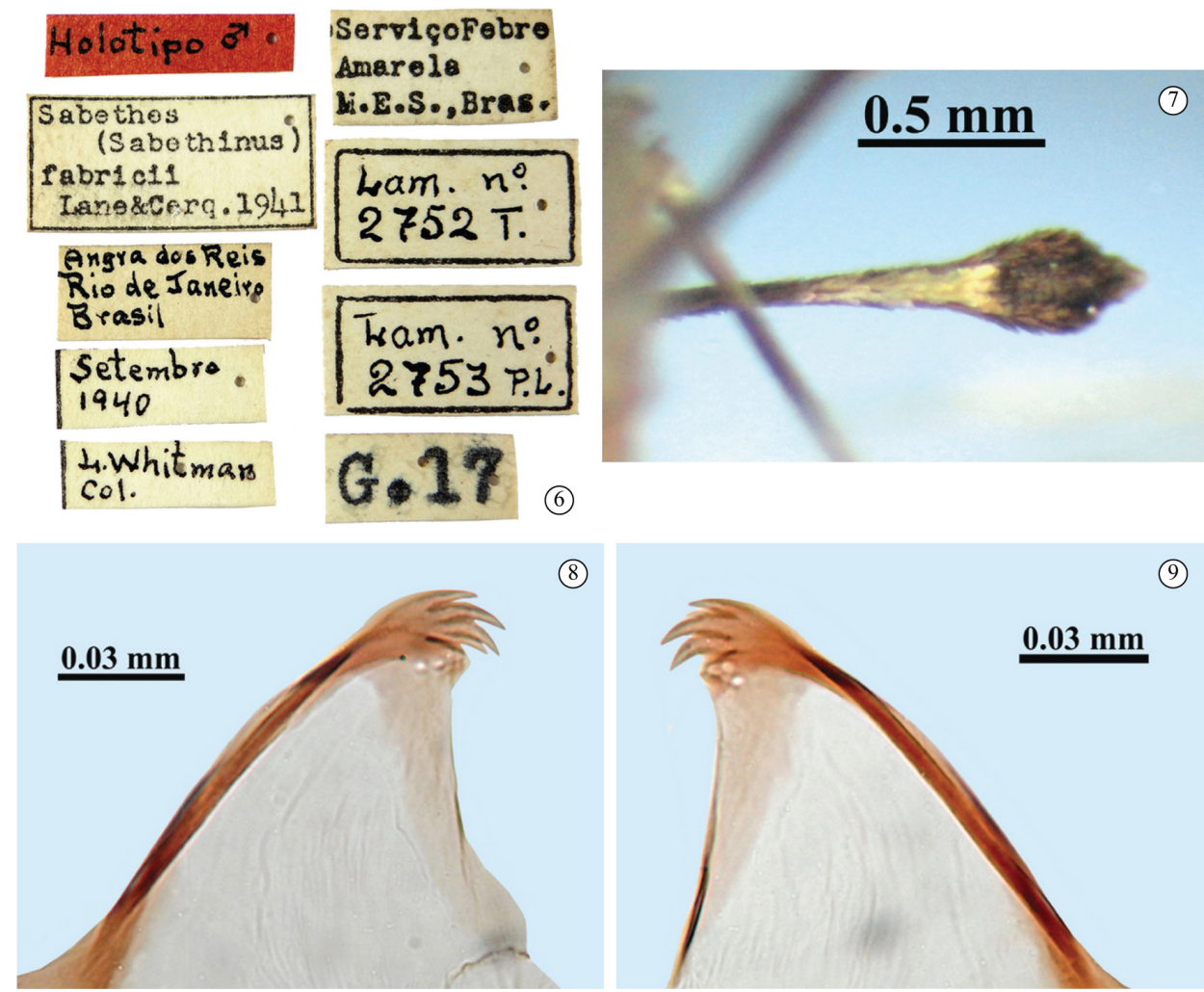

Figures 6-9. Holotype male of Sabethes fabricii Lane and Cerqueira. 6. labels; 7. proboscis, ventral view; 8 and 9. apex of proctiger. 
As already mentioned previously, the misinformation on these few characters of Sa. fabricii could result in difficulty or even error when identifying this species using the available keys for Sabethes spp. (Lane and Cerqueira, 1942; Lane, 1953; Forattini, 1965, 2002). As a result of the present work, including the examination of the types of Sa.fabricii, we have confirmed the following features of this species, which must be taken in account when using those keys: proboscis with a white spot beyond the middle and variably enlarged to the apex and may be spatulate in males (Figures 3, 4 and 7); setae over root of wing yellowish, which may be occasionally brownish, mainly in the basal portion; and proctiger ending in four teeth (Figures 5, 8 and 9).

As recorded here, immature forms of $\mathrm{Sa}$. fabricii were found naturally breeding in bamboo internodes. Although bamboo constitute a breeding place for several other species of mosquitoes, including Sabethes spp. (Lane and Cerqueira, 1942; Forattini, 1965, 2002; Harbach, 1994, 1995a, b; Hall et al., 1999; Lozovei, 2001; Müller et al., 2014), this is the first record of this natural Sa. fabricii breeding site to date.

Finally, the geographic distribution of Sa. fabricii, in accordance with the literature (Lane and Cerqueira, 1942; Lane, 1953; Guimarães et al., 2000) and with the new registered specimens in the present study, now includes the state of Minas Gerais in addition to the contiguous Brazilian states of Rio de Janeiro, São Paulo and Paraná (Figure 1).

\section{Acknowledgements}

We thank the Fundação de Amparo à Pesquisa do Estado do Rio de Janeiro - FAPERJ (contract 111.441/2013) and Conselho Nacional de Desenvolvimento Científico e Tecnológico (CNPq) for their financial support.

\section{References}

FORATTINI, O.P., 1965. Entomologia médica. São Paulo: Editora da Universidade de São Paulo, vol. 3, 415 p.
FORATTINI, O.P., 2002. Culicidologia médica. São Paulo: Editora da Universidade de São Paulo, vol. 2, 860 p.

GUIMARÃES, A.E., GENTILE, C., LOPES, C.M. and MELLO, R.P.M., 2000. Ecology of mosquitoes (Diptera: Culicidae) in áreas of Serra do Mar State Park, State of São Paulo, Brazil. II - Habitat distribution. Memórias do Instituto Oswaldo Cruz, vol. 95, no. 1, pp. 17-28. http://dx.doi.org/10.1590/S0074-02762000000100002. PMid:10656699.

HALL, C.R., HOWARD, T.M. and HARBACH, R.E., 1999. Sabethes (Peytonulus) luxodens, a new species of Sabethini (Diptera: Culicidae) from Ecuador. Memórias do Instituto Oswaldo Cruz, vol. 94, no. 3, pp. 329-338. http://dx.doi.org/10.1590/ S0074-02761999000300009. PMid:10419382.

HARBACH, R.E., 1991. A new subgenus of the genus Sabethes (Diptera: Culicidae). Mosquito Systematics, vol. 23, pp. 1-9.

HARBACH, R.E., 1994. The subgenus Sabethinus of Sabethes (Diptera: Culicidae). Systematic Entomology, vol. 19, no. 3, pp. 207-234. http://dx.doi.org/10.1111/j.1365-3113.1994.tb00588.x.

HARBACH, R.E., 1995a. A new Sabethes of the subgenus Peytonulus (Diptera: Culicidae) with an unusual fourth-instar larva. Entomologica Scandinavica, vol. 26, pp. 87-96.

HARBACH, R.E., 1995b. Two new species of the subgenus Peytonulus of Sabethes (Diptera: Culicidae) from Colombia. Memórias do Instituto Oswaldo Cruz, vol. 90, no. 5, pp. 583-597. http://dx.doi.org/10.1590/S0074-02761995000500007.

LANE, J. and CERQUEIRA, N.L., 1942. Os sabetíneos da América (Diptera, Culicidae). Arquivos de Zoologia do Estado de São Paulo, vol. 3, pp. 473-849.

LANE, J., 1953. Neotropical Culicidae. São Paulo: University of São Paulo. 1112 p.

LOZOVEI, A.L., 2001. Microhabitats de mosquitos (Diptera, Culicidae) em internódios de taquara na mata atlântica, Paraná, Brasil. Iheringia: Série Zoologia, vol. 90, pp. 3-13.

MÜLLER, G.A., MARCHI, M.J. and MARCONDES, C.B., 2014. Mosquito immature in bamboo internodes in eastern Santa Catarina, South Brazil (Diptera: Culicidae). Biotemas, vol. 27, pp. 151-154. 